\title{
Streamlining of air flow in the upper airways and trachea
}

\author{
R MARSHALL AND D J MACEY
}

From the Departments of Chest Diseases and Radiation Physics, Churchill Hospital, Oxford

ABSTRACT Streamlining of air flow in the upper airways and trachea has been investigated by inhaling ${ }^{81 \mathrm{~m}} \mathrm{krypton}$ through each side of the nose separately and counting over the lung fields with a gamma camera. ${ }^{81 \mathrm{~m}} \mathrm{Kr}$ inhaled through one nostril was uniformly mixed in the air stream by the time the carina was reached. Gas mixing occurs probably by a combination of diffusion and turbulent flow.

Some of the early investigators of the physiology of air flow in the nose and upper airways produced evidence that the airstream from the two sides of the nose remained separate in the pharynx and that the air entering through one nostril went mainly to the lung of the same side. $^{1-3}$ If this were true it would simplify ventilation scans of the lungs with ${ }^{81 m}$ krypton since, if the radioactive gas inhaled through one nostril went mainly to the lung of the same side, true lateral scans of the lung could be taken without appreciable interference from the other lung.

Mixing of the gas streams after leaving the two sides of the nose may occur as a result of turbulent air flow or by diffusion. Preliminary experiments were carried out using a model with streamline air flow to investigate the probable effects of diffusion.

\section{Methods}

MODEL OF STREAMLINE AIR FLOW

Air, and air containing ${ }^{81 \mathrm{~m}}$ krypton were fed at equal rates into a smooth bore tube of $19 \mathrm{~mm}$ internal diameter, approximating the diameter of the trachea (fig 1). In the first $9 \mathrm{~cm}$ of the tube the two gas streams were separated by a thin metal partition so that the gas flow was streamlined before the main tube was reached. Fifteen centimetres further down the tube the gas streams were divided by a thin "carina" aligned with the upper partition and the two gas streams conducted through plastic tubes lying on the collimator of a gamma camera. An activity profile

Address for reprint requests: Dr $\mathbf{R}$ Marshall, Department of Chest Diseases, Churchill Hospital, Oxford OX3 7LJ. across the two tubes was recorded using a Nokia multi-channel pulse height analyser and the $\mathrm{X}$ pulses. The ${ }^{81 \mathrm{~m}}$ krypton in each tube was calculated from the area of the profile at the site of each tube after subtraction of background counts.

INHALATION OF ${ }^{81 \mathrm{~m}} \mathrm{Kr}$

${ }^{81 \mathrm{~m}} \mathrm{Kr}$ has a half-life of 13 secs, so that a scan over the lung fields indicates the ventilation of each lung. ${ }^{4}$ Before inhalation of ${ }^{81 \mathrm{~m}} \mathrm{Kr}$ the resistance of each nasal passage was measured by posterior rhinometry. Pressure at the mouth was measured by a pressure transducer via a plastic tube round which the lips were closed. Nasal air flow was measured by a wire screen pneumotachograph connected to a nasal mask. ${ }^{5}$ The ${ }^{81 \mathrm{~m}} \mathrm{Kr}$ was inhaled through the apparatus shown iil fig 2. The outputs from the pneumotachographs, recording inspiratory air flow, were fed into the $X$ and $Y$ axes of a cathode-ray oscilloscope and the oscilloscope screen photographed. In practice the $X Y$ recording of flow through the right and left nostrils was linear showing that the ratio of flow through both nostrils was the same at all times during inspiration and thus the ratio of volumes inspired by the two nostrils was the same as the ratio of flow rates.

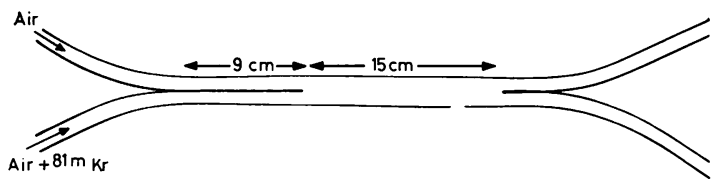

Fig 1 Diagram of air flow model. 


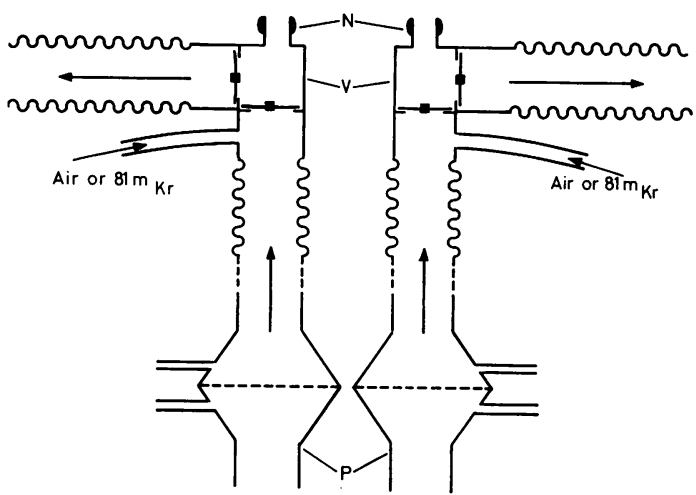

Fig 2 Diagram of test apparatus. $N=$ nasal applicator, $V=$ valve assembly, $P=$ pneumotachograph.

The ${ }^{81 \mathrm{~m}} \mathrm{Kr}$ was eluted continuously from the generator by a stream of air at 0.5 to $11 / \mathrm{min}$, passed along two metres of narrow bore tube, and fed into the corrugated tubing on the inspiratory side of the valve assembly just before the rubber flap valve. The subject was positioned centrally in front of the gamma camera to take a posterior view of both lungs. The valve assemblies were applied to the nostrils and the subject breathed with the mouth closed. ${ }^{81 \mathrm{~m}} \mathrm{Kr}$ was introduced into the inspired air to one nostril and after waiting about 30 seconds for equilibration the output of the gamma camera was recorded on videotape. After recording for 1-2 min the ${ }^{81 \mathrm{~m}} \mathrm{Kr}$ input was transferred to the other nostril without disturbing the subject and the camera output again recorded.

The videotape recordings were played back and counts made from equal areas of comparable regions in the right and left lung fields.

Measurements were made on four subjects with no signs or symptoms of nasal disease and with no significant abnormality in the ventilation and perfusion lung scans.

\section{Results}

The results of the model experiment are shown in fig 3.

The results of the lung scans and measurements of nasal resistance are shown in the table. Examination of the counts over the lungs shows that there is no appreciable difference in the count whether the ${ }^{81 \mathrm{~m}} \mathrm{Kr}$ is inhaled via the right or left nostril. ${ }^{81 \mathrm{~m}} \mathrm{Kr}$ in the dead space at the end of expiration has been shown to have only about $10 \%$ of the activity of the inspired gas and the reinspiration of this gas has a negligible effect on the distribution of radioactivity in the two lungs.

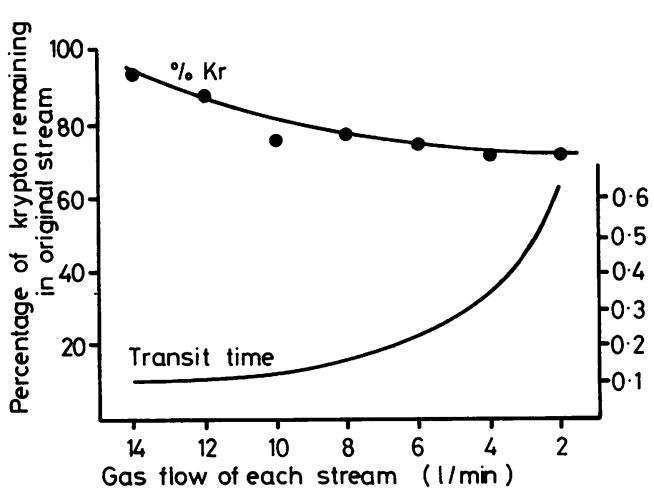

Fig 3 Results of model experiment.

Table Inhalation of ${ }^{81 \mathrm{~m}} \mathrm{Kr}$ through each nostril separately

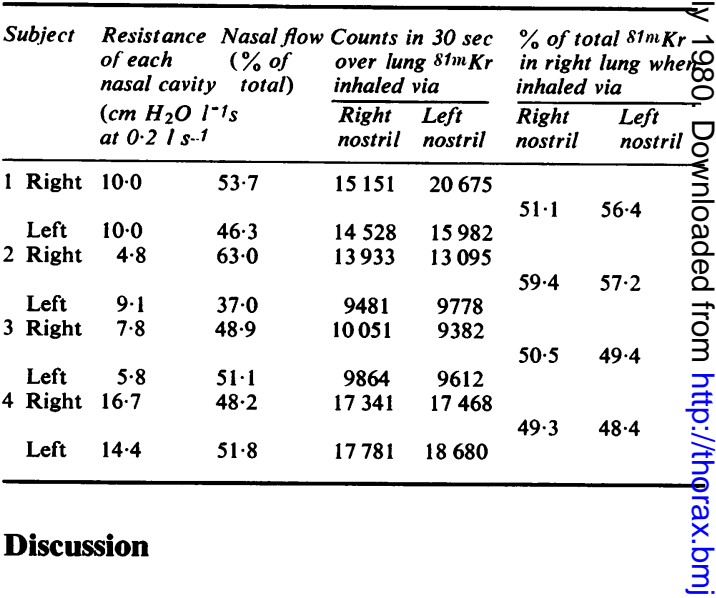

Preferential passage of air from one side of th: nose to the lung of the same side had been sug gested by Chauvet ${ }^{6}$ and some of the early investio gations on both man and animals seemed t $\vec{Q}$ support this theory. Mink ${ }^{1}$ used a wire covere with red litmus paper, held across the pharyn in various positions while breathing ammonio vapour through one nostril. From the change if colour of the litmus paper he was able to detere mine that the air stream after leaving the choand passed to the posterolateral part of the pharynx then came more anteriorly behind the tongue buf stayed on the same side of the pharynx. Wotzilkse and Schramek $^{2}$ investigated the deposition ofo carbon particles inhaled by rabbits through on nostril. The particles went mainly to the lung of the same side. Dishoeck ${ }^{3}$ found that carbon dusक inhaled through one side of the nose could be found on both sides of the pharynx but if on side of the nose was narrowed the carbon duse 
inhaled through that nostril stayed mainly on the same side of the pharynx and, he believed, went mainly to the lung of the same side. He carried out experiments breathing oxygen through one side of the nose and nitrogen through the other and showed that the gas expired through each nostril had the same composition. In that experiment further opportunity for mixing of the gas streams occurred during recombination of the streams from the two lungs and passage up the trachea. Before using ${ }^{81}$ krypton in the model experiment we made measurements, in two different models, with air passed down one side of the tube and $100 \%$ oxygen down the other. In all experiments, when the gas flow down each tube fell below $6 \mathrm{l} / \mathrm{min}$ the mixing of the streams increased rapidly so that at $21 / \mathrm{min}$ the streams had crossed over and the oxygen content of the stream was greater on the "air" side of the tube. This crossover was confirmed by using streams of (a) krypton in air and (b) $100 \%$ oxygen when $66 \%$ of the total krypton was present on the oxygen side of the tube as compared with only $27 \%$ when air was substituted for oxygen.

Mixing of the air streams leaving the two sides of the nose is caused by turbulent flow and by diffusion. The gas flow through models of the larynx remains streamline in spite of the narrowing at the cords ${ }^{7}$ although Proctor $^{8}$ states that some turbulence develops in the lower onethird of the trachea. In the model described in this paper, with a smooth walled tube of $19 \mathrm{~mm}$ diameter, Reynolds number does not exceed 2000 (the limit above which turbulent flow occurs in smooth tubes) until the flow rate down each side of the tube reaches $14 \mathrm{l} / \mathrm{min}$. In our model experiment mixing of the streams did not vary in relation to the transit time down the tube as would be expected if mixing occurred mainly by diffusion. In man the volume of the pharynx and trachea is of the order of $100-150 \mathrm{ml}$ which, with a minute volume of $61 / \mathrm{min}$ and with a duration on inspiration one-third of the total respiratory cycle, gives a transit time from nose to carina of $0.3-0.5$ seconds. In the model less than $30 \%$ of the krypton had passed into the opposite stream during this transit time. If gas flow in the upper airways of man was as smooth as in the model that we used one would expect a much higher concentration of krypton in the lung on the same side as the nostril through which the krypton is inhaled, than one would in the other lung. The measurements with ${ }^{81 \mathrm{~m}} \mathrm{Kr}$ show that the combination of diffusion and turbulent flow result in complete mixing of the gas streams from the two sides of the nose by the time that the gas reaches the carina, even in the subject in whom one nostril was relatively constricted. Thus the theory that inhalation of ${ }^{81 \mathrm{~m}} \mathrm{Kr}$ through one side of the nose might allow lateral scintigrams to be taken has been shown to be invalid.

\section{References}

1 Mink PJ. Physiologie der oben Luftwege. Leipzig: Vogel CW, 1920.

2 Wotzilka G, Schramek J. Tierexperimentelle Untersuchungen Uber den Weg des Inspirationsstromes jeder Nasenseite in die Lunge. Monatsschr Ohrenheilkunde Laryngo-Rhinologie (Osterreich) 1930; 64:580-5.

3 Dishoeck HAE van. The course of the inspired air and the possibility of the aspiration of mucopus from one side of the nose into the corresponding lung. Acta Otolaryngol 1939; 27: 414-21.

4 Fazio F, Jones T. Assessment of regional ventilation by continuous inhalation of radioactive krypton-81m. Br Med J 1975; 3:673-6.

5 Marshall R. A nasal mask for posterior rhinometry of each side of the nose separately. Rhinology 1980; in press.

6 Chauvet FPV. Relations pathogéniques entre les fosses nasales et la poitrine. Dissertation, Bordeaux 1919. Quoted by Uddströmer M. Nasal respiration. Acta Otolaryngol 1940; suppl 42: 1-146.

7 Birnmeyer G. Der Verlauf des Inspirationsstromes im Kehlkopf. Archiv Ohren, Nasen, Kehlkopfheilkd 1959; 174:369-74.

8 Proctor DF. The upper airways, II. The larynx and trachea. Am Rev Respir Dis 1977; 115: 315-42. 